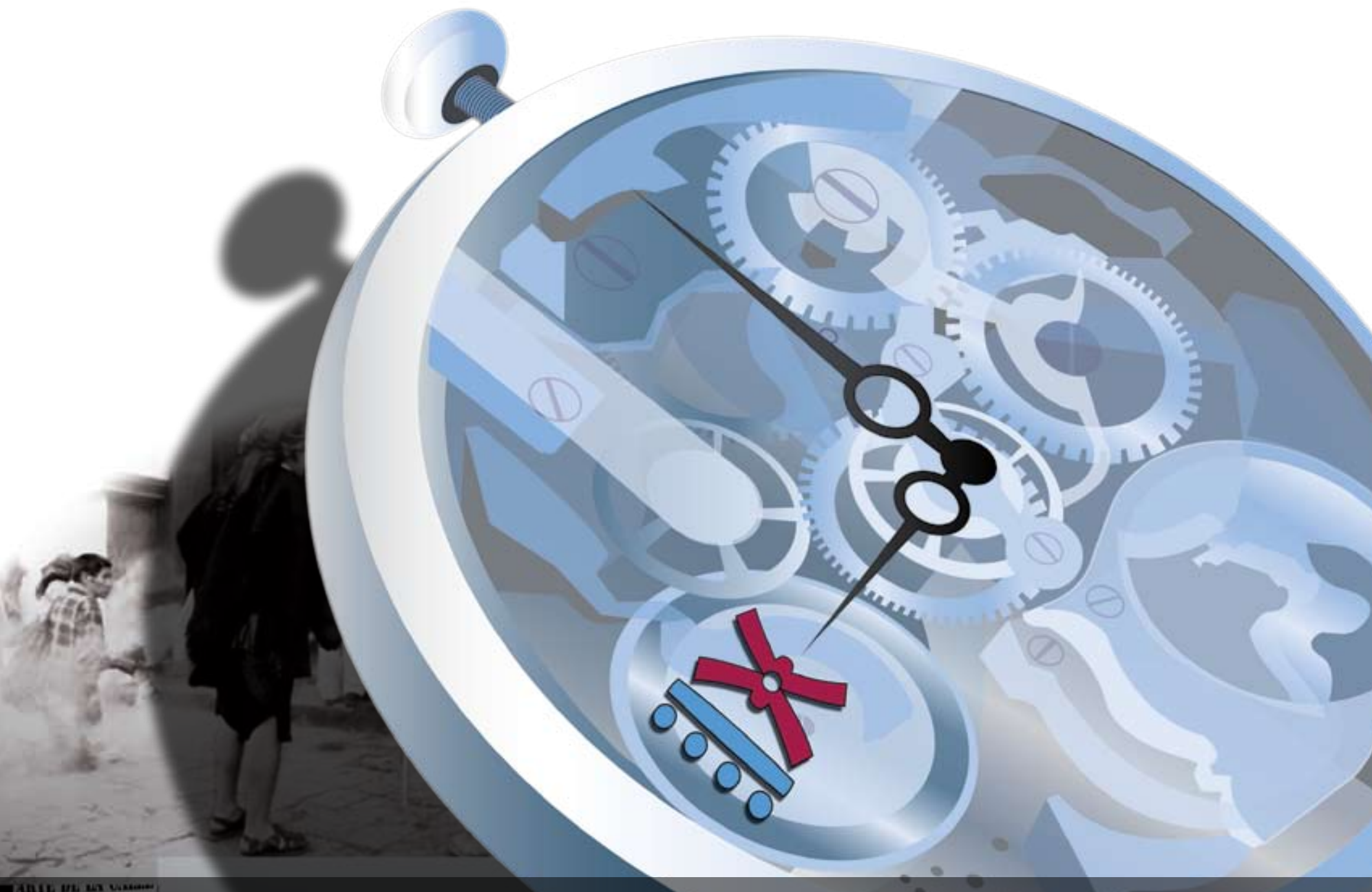

$9^{\circ}$ C O N G R ES O 2. CENTROAMERICANO DE H ISTO R I A

Universidad de Costa Rica ISSN 1409- 469X

Fecha de recepción: 15 de mayo 2008 Fecha de aceptación: 30 de mayo 2008

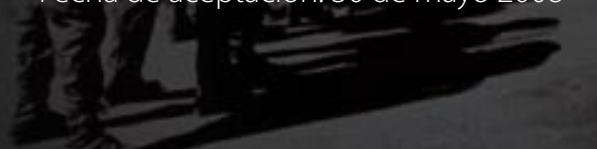

La importancia de las Excursiones Educativas como estrategia didáctica en la enseñanza de la Historia
Miembros del Consejo Editorial:

Dr. Ronny Viales, Dr. Juan José Marín

Editores Técnicos:

Allan Fonseca, Andrés Cruz, Gabriela Soto
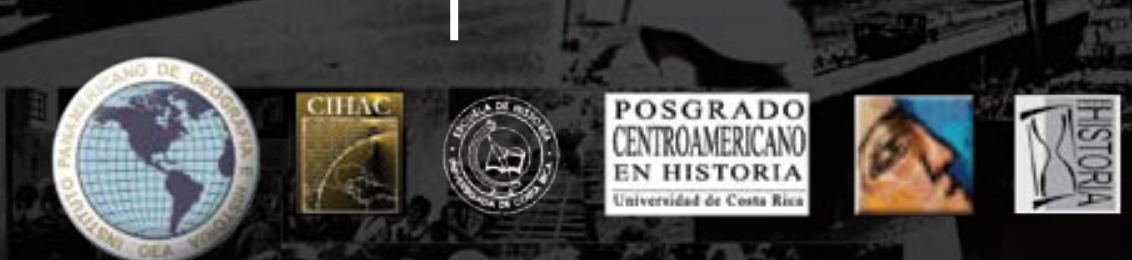
Indexaciones: Repositorio de Revistas UCR, DIALNET, Latindex, REDALYC Directorio y recolector de recursos digitales del Ministerio de Cultura de España, Directory of Open Access Journals. Diálogos Revista Electrónica de Historia ISSN 1409-469X. Número especial 2008. Dirección web: http://historia.fcs.ucr.ac.cr/dialogos.htm

\title{
"La importancia de las Excursiones Educativas como estrategia didáctica en la enseñanza de la Historia”
}

\author{
Autor: Profesor Amado Córdoba Berroa
}

Pasante de Maestría en Historia de Panamá y Centroamérica. Universidad Autónoma de Panamá. Dirección postal: Entrega General, Changuinola, Bocas del Toro, República de Panamá Telefax: (507) 758-5940

E-mail: amac 5@hotmail.com Universidad Autónoma de Chiriquí. 


\section{INTRODUCCIÓN}

El estudio de la Historia no se debe limitar a la simple memorización de datos, fechas y nombres, debe trascender a un plano en el cual el aprendizaje sea significativo y vivencial. En el marco de esta premisa podemos tomar como base la teoría Constructivista para implementar a nuestras clases de historia, metodologías más activas.

La concepción constructivista del aprendizaje escolar nos lleva a cavilar en aspectos como:

$>$ el reconocimiento de varios tipos y modalidades de aprendizaje

> replanteamiento de los contenidos curriculares orientados hacia "aprender a aprender"

$>$ revalorar el papel del educador, de un expositor y transmisor de conocimientos, a un facilitador u orientador hacia el aprendizaje.

De allí que los medios de enseñanza y su metodología sean de vital importancia para lograr aprendizajes significativos. Estos medios de enseñanza son múltiples y de diferentes aplicaciones, pero hemos elegido sustentar las excursiones o giras educativas y su importancia como estrategias metodológicas en la enseñanza de la Historia.

En correspondencia con lo anterior podemos plantearnos la siguiente interrogante:

¿En qué medida una excursión educativa lograría fortalecer el proceso de enseñanzaaprendizaje de la Historia y cómo ayudar las mismas a la internalización de los conocimientos en los educandos?

Para develar la respuesta a esta interrogante el autor se planteo como objetivo de esta investigación lo siguiente: 
- Demostrar la importancia de las giras educativas a través de las experiencias con los grupos de premedia $\left(7^{\mathrm{mo}}, 8^{\mathrm{vo}}\right.$ y $9^{\text {no }}$ grados) de la Changuinola American Academy (CAA) en diversas excursiones dentro y fuera de la provincia de Bocas del Toro, uniendo distintas materias escolares y enfatizando aspectos históricos - sociales de los lugares visitados.

Para el logro de este objetivo nos basaremos en las experiencias de las excursiones realizadas durante el año lectivo 2004 en la mencionada institución educativa a diferentes partes de la geografía nacional, tomando en cuenta las actividades previas y posteriores, así como también los informes presentados por los alumnos y alumnas.

Debemos también mencionar acuerdos interinstitucionales que buscan la mejora de la educación panameña, como el firmado entre el Instituto Panameño de Turismo (IPAT) y el Ministerio de Educación sobre Viabilidad Turística, es decir, garantizar una formación turística fundamental que facilite la comprensión de la actividad del sector turismo, de sus relaciones con el entorno natural, cultural e histórico, los recursos del medio ambiente, tecnológicos y su uso apropiado y el desarrollo social, económico y cultural del país. El proyecto esta destinado a los estudiantes de las escuelas oficiales y particulares de la educación básica general, ubicados en las zonas y centros turísticos.

Vemos pues, que este acuerdo busca que la cultura turística este institucionalizada en los planes y programas del Ministerio de Educación (MEDUCA), por lo que las excursiones educativas tienen un punto más de apoyo para su implementación en los centros educativos tanto públicos como privados.

Finalmente, queremos hacer patente la estructura del trabajo a saber:

- El Marco Teórico Referencial nos lleva a la definición de conceptos básicos para nuestra propuesta, así como aspectos fundamentales sobre el Constructivismo, como teoría de 
aprendizaje a utilizar. También incluimos la propuesta de clasificación de los medios de enseñanza de la Historia, enmarcados en el trabajo del profesor Horacio Díaz Pendás.

- La segunda parte versara sobre la solución teórica y practica de nuestra temática: "La excursión o gira educativa como estrategia metodológica en la enseñanza de la Historia" en base a las giras realizadas en el año lectivo 2004 en la Changuinola American Academy de la provincia de Bocas del Toro, institución bilingüe educativa en donde labora el autor. Finalmente, plantearemos la aplicación de las experiencias de una gira educativa al contexto de una clase.

Enla sección deConclusiones y Recomendaciones, es el resultado del análisis del trabajo realizado. En ella ofrecemos las consideraciones concluyentes del mismo y algunas recomendaciones que creemos podrían implementarse en beneficio de esta estrategia metodológica.

Finalmente, confiamos en que la consulta a este trabajo sirva de alguna manera al logro de una clase de historia más amenas y con mayor interés y aprovechamiento de parte de los alumnos y alumnas de nuestros cursos. 


\section{MARCO TEÓRICO REFERENCIAL.}

\section{a. Definición de conceptos básicos. Fuentes y Medios de enseñanza de la Historia.}

Lo primero que debemos tomar en cuenta para obtener un marco referencial en la elaboración de este trabajo es definir algunos conceptos. Veamos algunas de estas definiciones:

“Los Medios de enseñanza son aquellas fuentes del conocimiento

histórico que constituyen soporte material de los métodos de enseñanza"'

Otra definición de Medios de enseñanza nos dice que constituyen "elementos del proceso (...) y están conformados por un conjunto, con carácter de sistema, de objetos reales, sus representaciones e instrumentos que sirven de apoyo material para la consecución del objetivo" (Addine y otros, 1998).

Por otra parte, podemos definir fuentes como:

"Principios of fundamentos de una cosa"2

En el plano docente, encontramos fuentes de tipo oral, escritas, gráficas y audiovisuales.

Así, podemos afirmar que las fuentes primarias representan una excelente forma para procesar información de primera mano, en la cual debe intervenir la orientación del profesor y la habilidad y reflexión de los alumnos y alumnas.

La importancia de las fuentes nos la enfatiza el Doctor José Ignacio Reyes González de la siguiente manera:

"Las fuentes diversas para enseñar la Historia revelan la riqueza de métodos que permiten

1 Díaz Pendás, Horacio. "Las Fuentes y Medios en la Enseñanza de la Historia”. Material impreso, Postgrado Didáctica de la Historia, 2002.

2 Océano Uno Color. Diccionario Enciclopédico. Océano Grupo Editorial, S.A., Barcelona, 1998. Página 718. 
una enseñanza variada, diversificada. Son diversas las fuentes, tanto las históricas como del conocimiento histórico. En el primer grupo se encuentran los documentos, testimoniantes, objetos, filmes, monumentos, fotografías, entre otros que con un alto valor histórico permiten acercarse al pasado de los hechos y fenómenos históricos; esta información se encuentra generalmente en archivos, museos, galerías e instituciones de investigación histórica. El segundo grupo se refiere a las fuentes que reproducen originales, orales, mapas, manuales, diapositivas, filmes de ficción y documental, láminas, entre otros que aportan información al estudiante durante el aprendizaje de la asignatura.

Propiciar que el alumno consulta esas fuentes, investigue las problemáticas históricas a partir del trabajo con hipótesis, construya su conocimiento histórico desde una verdad objetiva, pero que de manera sencilla reproduce el camino de los investigadores es una máxima que entrena al estudiante a cómo moverse con los conocimientos sociales.

El trabajo en pequeños grupos y las tareas individuales de acuerdo con el diagnóstico del escolar favorecen el aprendizaje consciente, el dominio no solo de los elementos conceptuales del conocimiento, sino además los procedimentales y actitudinales. "”

Para desarrollar un pensamiento histórico creador debemos utilizar un adecuado método de enseñanza - aprendizaje. Por lo que esto nos lleva a definir este de la siguiente manera:

"El Método representa el componente ejecutor del proceso docente e integra , de forma sistemática, la estructura y organización de las acciones que realiza el maestro y los alumnos.

Los métodos se encargan de llevar a cabo la orientación del proceso.

Traduce las metas a lograr y la selección hecha de conocimientos y

3 Reyes González, José Ignacio. " Problemas actuales de la didáctica de la Historia”. http:/www.didacticahistoria.com/ccss33.htm (Fecha de acceso: 30 enero 2003) 


\section{Habilidades en procederes del alumno y de su profesor"}

Tal y como se ha planteado anteriormente, no podemos limitar la enseñanza de la Historia a la repetición de contenidos que plasman los libros de texto, debemos utilizar variedad de métodos de enseñanza que lleven al alumno y alumna a lograr aprendizajes significativos, vivenciales y que además de ser interesantes, internalizen los mismos. Esto se logra aplicando métodos de enseñanza activos, acorde con teorías como el Constructivismo.

\section{b. El Constructivismo como teoría de aprendizaje.}

Debemos iniciar observando aspectos básicos sobre esta teoría. Según Carretero (1993), el Constructivismo es " la idea que mantiene que el individuo - tanto en los aspectos cognitivos y sociales del comportamiento como en los afectivos- no es un mero producto del ambiente ni un simple resultado de sus disposiciones internas, sino una construcción propia que se va produciendo día a día como resultado de la interacción entre otros factores."

Otros autores resumen parte de esta teoría en tres postulados, a saber:

1. El constructivismo se basa en la idea de que al aprender se transforma el conocimiento. Esta transformación, a su vez, ocurre a través del pensamiento activo y original del aprendiz. La educación constructivista implica la experimentación y la resolución de problemas considerando que los errores son parte de la educación y se aprende de ellos.

2. Los estudiantes comprenden mejor cuando están envueltos en tareas y temas que cautivan su atención, que les interesa. Por lo tanto, los docentes deben saber lo que interesa a sus estudiantes y, a partir de allí, relacionarlos con los contenidos curriculares.

3. El docente debe fomentar la libertad responsable. La autonomía se desarrolla a través

4 Álvarez de Zayas, Rita Marina, en "Tendencias actuales de la Didáctica de la Historia". Postgrado de Didáctica de la Historia, 2002. 
de las interacciones con otros miembros de la sociedad para desarrollar los conceptos de igualdad, equidad, justicia, democracia y cooperación.

La enseñanza de la Historia en base a la teoría constructivista fue plasmada, entre otros, por David Paul Ausubel (1918 - ) al hablar del "Aprendizaje Verbal Significativo”, que se produce cuando se relacionan los nuevos conocimientos que se van a aprender con conocimientos ya existentes en la estructura cognitiva de los estudiantes, los cuales pueden ser el resultado de experiencias educativas anteriores, escolares y extraescolares o, también, de aprendizajes espontáneos.

Vemos que algunas propuestas constructivistas son fundamentales para que este proceso de enseñanza - aprendizaje sea significativo, como las planteadas a continuación:

- Las experiencias previas del estudiante deben estar ligadas a sus vivencias personales y sociales

- La selección de los contenidos de la Historia se deben organizar en torno a una red conceptual, convirtiéndolos en significativos para el alumno

- El verdadero artífice de su aprendizaje y de la construcción del conocimiento, es el estudiante

- Lograr que los conocimientos científicos sean funcionales y se puedan utilizar fuera del contexto escolar y, que los alumnos utilicen la manera lógica y comprensiva.

_Por todo lo anterior descrito, se concluye que la función del docente y los estudiantes es complementaria, dado que el primero dispone los contenidos que el segundo deberá reelaborar, por medio de diversas actividades en las que se combinan estrategias metodológicas de exposición o recepción, de descubrimiento y de indagación, y dentro de esta coyuntura enmarcamos nuestra investigación sobre las giras educativas como metodología didáctica en 
la enseñanza de la Historia.

\section{c. Clasificación de los Medios de Enseñanza de la Historia.}

En esta parte de nuestro trabajo nos basaremos en el criterio de clasificación de los medios de enseñanza de la Historia propuesto por el profesor Horacio Días Pendás en "Las fuentes y medios de enseñanza de la Historia".

El profesor Días Pendás nos explica que las fuentes primarias son usadas por los educadores como medios de enseñanza y puntualiza que estas son:

1. Los objetos originales más concretos de la cultura material: piezas de museo: (evidencias arqueológicas, armas de una época, ropa, instrumentos, etc.)

2. Fuentes primarias de naturaleza audiovisual: filmes sonoros, quinescopios, videos, tiras fílmicas y series de diapositivas sincronizadas con sonido

3. Imágenes sin sonido: películas silentes, fotos, diapositivas, pinturas, ilustraciones, caricaturas

4. Fuentes primarias gráficas o simbólicas: documentos escritos, publicaciones periódicas de una época, mapas, croquis, etc.

5. Fuentes primarias orales.: testimonios orales, discursos, grabaciones.

En segunda instancia tenemos las fuentes del conocimiento elaboradas con fines didácticos, cuyo contenido es válido para la enseñanza pero no para la investigación histórica:

1. Reproducciones de los objetos originales más concretos. Por ejemplo: las reproducciones de vasijas aborígenes

2. Medios audiovisuales: comprenden las producciones de ficción como lo son las películas, 
emisiones de televisión, series de diapositivas o tiras fílmicas sincronizadas con sonido, cuyo ajuste a la verdad científica las haga confiables para el proceso de aprendizaje

3. Imágenes sin sonido: películas silentes, láminas, diapositivas, tiras fílmicas, pinturas, ilustraciones, caricaturas

4. Medios gráficos o simbólicos: libros de texto, bibliografía especializada, fichas de contenido de las mismas, programas de computación para la enseñanza, cuadros sinópticos, tablas cronológicas, comparativas y sincrónicas: gráficos estadísticos, esquemas lógicos, etc.

5. Medios auditivos: la palabra oral, grabaciones, emisiones radiales.

Sobre la base de lo anteriormente expuesto, esgrime el profesor Días Pendás que la estimulación de los alumnos se debe dar a través, no solo de los libros de texto, en donde el conocimiento esta procesado, sino que también trabajando y aprendiendo de las fuentes primarias, las que nos brindan un marco vivencial en la realidad circundante.

\section{Las Fuentes Históricas en calidad de medios de enseñanza.}

Son muchas las fuentes históricas que se pueden utilizar en calidad de medios de enseñanza de la Historia, pero como nuestro trabajo esta centrado en las giras o excursiones educativas, acotaremos lo que el profesor Días Pendás y otros autores nos explican sobre las fuentes que podríamos relacionar con este tipo de actividades.

\subsection{Museos}

En primera instancia, compilaremos información sobre la visita a los Museos. Siguiendo la idea de relacionar nuestras actividades a la teoría Constructivista, veamos que plantea el Constructivismo para los Museos:

a. Que se motive a los visitantes a que den significado a sus experiencias, realizando visitas incentivadoras. 
b. Que se propicie una relación significativa entre la exhibición y el conocimiento previo que el visitante tiene al respecto

c. Identificar a los museos como centros de aprendizaje no formal

d. Que se profundice en los conocimientos previos del visitante, evaluando la participación de éste para mejorar futuras exposiciones

e. Que se faciliten situaciones en las que se ponga en juego el aprendizaje y la interacción social. ${ }^{5}$

Los museos de Historia nos presentan una excelente combinación entre objetos originales con textos explicativos, fotografías, mapas, tarjas, murales, etc. Estos elementos deben constituir un sistema de medios para la enseñanza de la historia.

El profesor Días Pendás recomienda como formas de trabajo en los museos:

- La visita guiada

- Trabajo del estudiante independientemente apoyado en una guía de observación

- La clase vinculada al Museo.

Muy importante es la labor del educador antes de la visita, pues debe estudiar el contenido del Museo, correlacionándolo con las unidades del programa educativo de la asignatura y así determinar que contenidos del mismo se reafirman con la visita. Otro factor importante es el tiempo. Se debe otorgar el suficiente a los alumnos para observar, comentar, anotar, interpretar y analizar las exposiciones museísticas, en miras a lograr que el mensaje de estas fuentes llegue al alumnado.

En los casos que nos atañen, o sea, las experiencias de la CAA, se les preparaban preguntas previas (evaluación diagnóstica) que los motivaran sobre el contenido del Museo a visitar, luego,

5 Delgado, Ruth. "Recursos Didácticos para Museos Eclesiásticos". http:/www.naya. org./congreso2002/ponencias/ruth_delgado.htm (Fecha de acceso: 20 enero 2003) 
en el Museo en sí, se les daba una pequeña introducción por parte del profesor y nos apoyábamos en las explicaciones de los guías de cada lugar visitado. Los estudiantes tenían completa libertad para cuestionar y profundizar sobre los temas que a su concepto fueran más interesantes de las diferentes exposiciones, teniendo en cuenta que cada visita sería parte del informe final a presentar días después, en nuestra escuela.

\section{Sitios históricos y arqueológicos.}

En Panamá existen buena cantidad de sitios históricos y arqueológicos, por lo que una visita o gira a alguno de estos, representa una fuente inagotable de experiencias y conocimientos. Como plantea el profesor Días Pendás, el solo salir de los muros de la escuela es una estimulante actividad de aprendizaje.

Preguntas claves y orientadoras lograran producir excelentes resultados, plasmados en informes de campo, futuras exposiciones verbales y fotográficas, tanto en la escuela a compañeros de otros niveles, como a la comunidad, contribuir a la valorización del patrimonio histórico y cultural del país, al igual que podría ayudar al estudiante a descubrir afinidades o inclinaciones, en miras a sus futuras carreras como historiadores, ecologistas, biólogos, arqueólogos, antropólogos, en fin, profesiones relacionadas con la historia y la cultura.

El procedimiento metodológico, según el autor citado, debe ser parecido al utilizado con las fuentes museísticas con precisión de objetivos, itinerarios y tareas a cumplir por los alumnos y alumnas.

\section{Comunidades.}

Otra fuente primaria de información lo son las comunidades. Algunas acepciones que se le han dado al término comunidad, están las siguientes: 
"Junta o comunidad de personas que viven unidas bajo ciertas reglas" 6

Una definición más acorde a las Ciencias Sociales nos dice que Comunidad es:

“... un organismo social que ocupa determinado espacio geográfico. Esta

influenciada por la sociedad, de la cual forma parte, y a su vez funciona

como un sistema, más o menos organizado, integrado por otros sistemas

de orden inferior -las familias, los individuos, los grupos, las organizaciones

e instituciones- que interactúan, y con sus características e interacciones

definen el carácter subjetivo, psicológico de la comunidad, y a su vez

influyen, de una manera u otra, en el carácter objetivo, material, en depen-

dencia de su organización y su posición -activa o pasiva- respecto a las

condiciones materiales donde trascurre su vida y actividad"

En correspondencia a lo anterior, destacamos la importancia de las comunidades, con sus características sociales, económicas, históricas, geográficas, etc. De allí la propuesta a realizar expediciones o giras educativas para resaltar aspectos de estos tipos. Cabe destacar el carácter interdisciplinario que se le puede dar a visitas a comunidades, especialmente teniendo en cuenta la diversidad de las mismas que encontramos en el territorio nacional y la multiplicidad de 6 Diccionario Uno Color, página 406.

7 Arias Herrera, Héctor. "La Comunidad y su estado. Personalidad- Educación, Salud. Citado en: "Geografía: alternativas para el trabajo docente". La Habana, 2000, página 27. 
aspectos que pueden ser abordados, claro esta, siguiendo los pasos o procedimientos acotados con anterioridad.

\section{a. La excursión o gira educativa como estrategia metodológica en la enseñanza de la}

\section{Historia: experiencias en la Changuinola American Academy.}

Iniciamos este segundo capítulo realizando una pequeña reseña sobre la Changuinola American Academy (CAA).

La CAA es una escuela de carácter privado, es decir, de la llamada Educación Particular, adscrita al Ministerio de Educación de la República de Panamá. Se encuentra ubicada en el distrito de Changuinola, provincia de Bocas del Toro; en ella se imparte una educación bilingüe, con un llamado "sistema americano", en el cual la mayoría de las materias o asignaturas se imparten en el idioma inglés, a excepción de Ciencias Sociales, Historia, Geografía, Español, Folclore, Educación Física y Música.

Esta escuela fue fundada a finales de la década de los 40 's para brindarle educación a los hijos de los empleados administrativos de la United Fruit Company (actual Bocas Fruit Company) de la cual la escuela es un departamento administrativo. En la actualidad la escuela cuenta con una matrícula de 180 alumnos, un cuerpo docente y administrativo de 25 personas. 
Hacemos estas aclaraciones para sustentar algunas particularidades que observa este centro educativo. Por lo general, los alumnos y alumnas son hijos e hijas de los administrativos de la Bocas Fruit Company (filial de la multinacional Chiquita Brands) o de personas de la comunidad con cierta solvencia económica, por lo que en la mayoría de los casos, al momento de planear la realización de una excursión o gira educativa dentro o fuera de la provincia, resulta más fácil el financiamiento por parte de los padres de familia, de allí que se puedan realizar 2 o 3 excursiones en el año escolar.

Teniendo en cuenta lo anteriormente expuesto, procederemos a explicar las experiencias de las excursiones o giras educativas realizadas en la CAA durante el año lectivo 2004.

En primera instancia, debemos ubicar geográficamente la provincia de Bocas del Toro. Se encuentra en la parte noroeste de la República de Panamá y es, junto a la provincia de Chiriquí, limítrofe con la República de Costa Rica, al oeste. Nuestras giras cubrieron lugares a las provincias de Chiriquí, Herrera, Los Santos y Coclé. A medida que vayamos adentrándonos en el trabajo, especificamos más sobre los lugares visitados y las actividades realizadas. Estas excursiones o giras educativas fueron de carácter multidisciplinarias, pues, implicaban actividades en asignaturas como Ciencias Naturales, Literatura, Negocios, Geografía y por supuesto, Historia.

Una excursión o gira educativas pertenece al grupo de actividades y recursos preferentemente de observación, y como todo elemento didáctico, debe llevar una sistematización en su preparación, es decir, plantear objetivos, los contenidos a relacionar con nuestro programa educativo y las actividades previas, durante y posteriores a la visita. 
En los casos que nos competen, estas actividades se planteaban previamente, ya que para obtener el aval de la dirección del plantel y de los padres de familia, el equipo de profesores presentamos el itinerario de visitas y tareas a cumplir. Luego de obtener los estos permisos, aunque la excursión o gira es de carácter multidisciplinario como hemos acotado anteriormente, cada educador prepara minuciosamente cada actividad a realizar en cada sitio, así como las tares correspondientes a las mismas tanto en el lugar, como en la escuela al finalizar el viaje. Para esto se utiliza la correlación entre sitios y aspectos a observar y los contenidos de clases; un instrumento de mucha utilidad es la Guía de observación, no solo utilizada en la visita a los museos, sino también a comunidades, sitios históricos y arqueológicos, Iglesias, etc., claro esta, adecuando esta a cada caso en particular.

Muy importante son las conversaciones previas al viaje con los estudiantes sobre la disciplina y la forma de comportarse durante la gira, siguiendo los lineamientos del Reglamento de Conducta de nuestra institución educativa.

Durante las visitas a los lugares elegidos, los alumnos y alumnas toman apuntes y realizan sus observaciones, orientados con la guía previamente entregada, y por supuesto, a través de sus propias conclusiones y análisis, recordando que estos apuntes les servirán en la confección de sus informes y otros trabajos futuros relacionados con la gira, los cuales pueden consistir tanto de trabajos escritos, como en la confección de Murales Informativos dentro de la escuela y exposiciones sobre aspectos sobresalientes e interesantes de las giras a otros compañeros dentro de la escuela o de otras instituciones. 


\section{Excursiones educativas realizadas durante el año lectivo 2004.}

La primera excursión realizada en el año 2004 se realiza durante el primer bimestre académico, precisamente durante el mes de abril. La misma se efectuó hacia la provincia de Chiriquí, específicamente al sector conocido como Tierras Altas, en el corregimiento de Volcán, distrito de Bugaba.

La información completa sobre está gira, la podemos encontrar en el punto b de este capítulo, pues la tomamos como modelo para la implementación del desarrollo de una clase. Además del objetivo recreacional y turístico, se visitaría un sitio arqueológico, en la población de Barriles.

La ubicación del Sitio y su descripción es la siguiente:

"El Sitio de Barriles (BU-24) esta en el área suroeste de la región del volcán

Barú, cerca al poblado de Nueva California, a $8^{\circ} 7^{\prime}$ latitud norte y $82^{\circ} 41^{\prime}$

Longitud occidental. Una quebrada llamada Barriles (por las piedras

labradas en forma de barriles encontradas en el sitio) corre al sur del área

ocupada. La elevación del sitio es de 1200 a 1300 metros sobre el nivel del

mar. Barriles fue descrito por primera vez por Stirling (1950) como un "centro

ceremonial" consistente en un área levantada de aproximadamente $50 \times 30$

yardas, limitada por piedras lajas y grandes piedras redondeadas(...)"”

$8 \quad$ Rosenthal, E.J. Report number 5. Excavations at Barriles (BU -24) : A small testing program. En "Adaptative Radiations in Prehistoric Panama". Cambridge, Massachussetts, 
Otra descripción del Sitio Barriles nos la ofrece Gladys Casimir de Brizuela y es del tenor siguiente:

"Barriles coyo origen se remonta a decenios anteriores a la era cristiana,

llegó a convertirse en un importante centro ceremonial, entre el $600 y$

800 d.C. El centro tenía estructuras con pies de lajas de piedra; de allí

procedian grandes metates finamente tallados, "barriles" de piedra y lo

más significativo, las esculturas de personajes que son llevados a

horcajadas por servidores. Estos personajes tienen gorros cónicos en

la cabeza, pectorales y en las manos, cabezas humanas y hachas. Se

trata de caciques que exhiben cabezas trofeos de sus rivales",

Por lo anteriormente expuesto, podemos concluir que el Sitio Barriles es uno de los más importantes dentro del patrimonio histórico nacional, por lo que una visita al mismo, de existir las posibilidades, es sumamente interesante.

El Sitio se encuentra dentro de una propiedad privada, perteneciente a la familia Landao, la cual, consiente de su papel como guardianes del patrimonio nacional , han implementado una exhibición en el sitio, asesorados por autoridades universitarias locales e internacionales. Esta actividad de la familia Landao nos permite adentrarnos en la educación en valores, al resaltar

Harvard University Printing Oficce, 1980. página 228 (Traducción del autor).

9 Casimir de Brizuela, Gladys. "Arqueología y Etnohistoria de Panamá”. Editorial Universitaria, Panamá, 1998. página 35. 
entre otros: la responsabilidad, el sentido de pertenencia, la responsabilidad ambiental y la laboriosidad demostrada por ellos.

Esta gira se realizo en dos días, pues la distancia entre Changuinola y Volcán es de aproximadamente 260 kilómetros. Cabe destacar que esta era la parte de Historia de la excursión, que como hemos anotado anteriormente, son de carácter multidisciplinario.

Una segunda excursión educativa se realizó durante el tercer bimestre, entre el 18 y el 22 de septiembre de 2004. Esta gira se dirigió hacia las llamadas "provincias centrales" (Herrera, Los Santos y Coclé) de nuestro país. Los estudiantes de premedia (7 $7^{\mathrm{mo}}, 8^{\mathrm{vo}}$, y $9^{\text {no }}$ ) eran los protagonistas de la misma. Escogimos estas provincias por considerarlas las cunas del Folclore panameño, además de la diversidad de museos, sitios históricos, iglesias coloniales y parques naturales existentes en la región.

Algunos datos sobre estas provincias los podemos sintetizar así:

\begin{tabular}{|c|c|c|c|}
\hline Provincia & Capital & $\begin{array}{c}\text { Población } \\
(2000)\end{array}$ & $\begin{array}{r}\text { Superficie } \\
\text { aprox. en kms }{ }^{2}\end{array}$ \\
\hline Coclé & Penonomé & 202461 & 4927.4 \\
\hline Herrera & Chitré & 102465 & 2340.8 \\
\hline Los Santos & Las Tablas & 83495 & 3805.4 \\
\hline
\end{tabular}

Fuente: Panamá en Cifras. Censos 2000. Contraloría General de la República. Dirección de Estadística y Censo. Panamá, 2001.

Durante esta gira tuvimos como centro de operaciones la ciudad de Chitré, capital de 
la provincia de Herrera, de donde salimos diariamente hacia los lugares a visitar y en donde pernoctábamos.

Siguiendo los pasos ya establecidos en cuanto a la preparación del grupo para las visita a cada lugar, realizábamos las actividades previas, durante y posteriores a la visita, apoyándonos en guías de observación adaptadas a cada lugar, fotografías como apoyo para los informes y en algunos casos, cámaras de video y grabadoras.

A continuación, destacamos algunos datos sobre los lugares visitados:

\section{Provincia de Herrera:}

Parque Nacional Sarigua: fundado bajo Ley 72, del 2 de octubre de 1984, tiene una extensión aproximada de 8000 hectáreas. Sarigua significa sal y agua, es una zona desprovista de vegetación en todo su perímetro y de tierra arenosa rojiza. Sarigua se forma al entrar agua salada por los manglares día tras día, al pasar los aguajes y al quedar residuos de los mismos, el sol evapora el agua quedando pequeñas capas de sal, formándose así el fenómeno de desertificación, que en temporada de lluvias es arrastre del suelo y en temporada seca es el levante de polvo el cual contiene sal y perturba la vegetación, impidiendo su fotosíntesis y haciendo que la vegetación vaya decayendo y sea perturbado su desarrollo natural.

* Visita al pueblo de La Arena (6 429 habitantes) donde destacamos la confección de artesanías y cerámicas, famosas en todo el país. 


\section{Provincia de Los Santos}

Museo de la Nacionalidad: fundado el 10 de noviembre de 1974, se encuentra en la calle José Vallarino en la Villa de Los Santos. Su gestora fue la ilustre antropóloga Reina Torres de Araúz. Se ubica en la vieja casa del Concejo Municipal de Los Santos, tiene una exhibición de hechos históricos de la Independencia de Panamá de España.

* Iglesia de Santa Librada y la ciudad de Las Tablas, capital de la provincia y sede del carnaval tableño, el más importante del país.

\section{$\underline{\text { Provincia de Coclé }}$}

Fábrica Nestlé: esta fábrica inicia operaciones el 27 de julio de 1938. su principal actividad es el procesamiento de productos de leche y jugos de frutas, para el consumo nacional y a nivel centroamericano.

- Natá de los Caballeros: ciudad fundada en 1522 por Pedro Arias De Ávila cuyo objetivo era:

“ ... detener la rebeldía de Urraca y sus aliados para proceder, con mínimo de riesgos, a la exploración en busca de las minas de oro que había en la región"10

Destacamos en Natá de Los Caballeros, su iglesia, la más antigua del continente americano, restaurada a finales de los años 90's. Esta mantiene su arquitectura y decorado, que se compone de pinturas traídas de Perú, piezas, figuras e imágenes,

10 Casimir de Brizuela, Gladys. Página 86. 
altares, nichos originales de la época tallados totalmente en madera.

* Casa Museo Santa Rosa: localizada en la comunidad de El Roble, Aguadulce, es una réplica de una casa de principios del siglo XX, específicamente de la casa de la familia Del Valle, con fotografías, muebles, artículos de la época y maquinarias antiguas relacionadas con la actividad de un Ingenio de azúcar. Abrió sus puertas el 11 de noviembre de 1994 y se encuentra en los terrenos del Ingenio azucarero Santa Rosa.

Durante todas las visitas descritas, los estudiantes tuvieron la oportunidad de profundizar sobre aspectos históricos, económicos, sociales y científicos de los sitios visitados, resaltando el valor de cada uno de ellos a través de diferentes consideraciones, tal como lo plasmamos en el ejemplo de implementación en nuestro punto b del presente capítulo.

Cabe destacar que vistas de estos lugares las podemos apreciar en los anexos, donde incluimos una reseña fotográfica de los mismos.

La tercera y última excursión que realizamos en el año lectivo 2004, fue con el grupo de $7^{\text {mo }}$ (11 a 13 años), a mediados del mes de noviembre. La misma consistió en una gira socio-histórica por ferrocarril en el trayecto Changuinola - Almirante. Este ferrocarril data de principios del siglo XX (1905-1909) cuando simultáneamente se construye el puerto de Almirante para el comercio del banano hacia los Estados Unidos y Europa.

El trayecto fue de aproximadamente 21 kilómetros y es interesante destacar que se siguen utilizando los mismos puentes y la vía férrea original. Existe un vagón para el traslado de personas a comunidades que nacieron a orillas de la vía y que no tiene acceso vía carretera. 
En esta gira se intentaba destacar el papel del ferrocarril para las comunidades por las cuales atraviesa, así como el aspecto bio-geográfico del área a recorrer.

\section{b. Implementación de una excursión en el marco del desarrollo de una clase}

\section{clase de Historia.}

Procedemos ahora a presentar la implementación de una clase basada en una gira didáctica, en este caso en particular, lo haremos en base a la primera excursión del año lectivo 2004 a la provincia de Chiriquí y en particular al Sitio Barriles.

\section{INTRODUCCIÓN}

Las giras educativas de campo son de trascendente importancia como estrategia metodológica en la enseñanza de la Historia.

Dentro del Aprendizaje Desarrollador, el paradigma es el desarrollo integral del alumno, prepararlo para la vida, lograr la máxima de "aprender a aprender".

Tomando en cuenta las facilidades con que cuentan mis alumnos de la Changuinola American Academy, se propuso una visita al sitio Barriles, sitio arqueológico al suroeste del Volcán Barú, provincia de Chiriquí, con los grupos de 8vo y 9no años.

La visita a este sitio arqueológico, considerado el centro ceremonial más importante del 
occidente panameño, permitirá que los alumnos profundicen sus conocimientos sobre la estatuaria encontrada en él, así como su cerámica, petroglifos, metates y ambiente geográfico en que se desarrollo esta cultura, que forma parte integral de nuestro patrimonio arqueológico.

Los alumnos podrán caracterizar objetivos de análisis, tomando en cuenta que los grupos asistentes a la gira promedian entre los 13 y 16 años de edad, que los llevaran a concluir sobre las relaciones existentes entre este sitio, conocido en la clasificación arqueológica como BU-24, con otros de los alrededores y como la cultura asentada allí, logro llegar al pináculo del desarrollo artístico y quizás social del área del Volcán Barú.

Analizaremos, asimismo, el papel de la familia Landao como custodios de este patrimonio, el rol por ellos asumido como garantes de la difusión y conservación de nuestra herencia cultural, latente en las muestras arqueológicas encontradas en el área.

De igual manera, definiremos los valores a desarrollar y que se encuentran inmersos en las actividades allí realizadas, tanto en el pasado histórico (Cultura Barriles), como en el presente (Familia Landao).

A la vez fundamentaremos la metodología de trabajo con las fuentes y medios en la Enseñanza de la Historia, en este caso una fuente primaria como lo es el Sitio arqueológico en mención.

Parte de esta actividad la constituye el aprovechamiento de esta importante fuente, que es el Sitio Arqueológico, a través de los lineamientos establecidos para las visitas a sitios históricos.

\section{FUNDAMENTACIÓN.}

Siguiendo los lineamientos y exigencias para lograr un aprendizaje desarrollador podemos señalar lo siguiente:

En la parte diagnostica, la gira cumple su objetivo pues enlaza los conocimientos previos de clase con los nuevos en el campo. 
A través de las orientaciones de las guías del sitio y del profesor, se propicia la búsqueda activa del conocimiento por el alumno.

Reflexionaran sobre la evolución de los grupos que vivieron en la zona y las posibles causas de su repentina inmigración.

$>$ Mediante el pensamiento lógico, podrán concluir sobre la estratificación social que se daba en esta zona, patente en la estatuaria encontrada en el sitio.

Todo esto se lograra a través de un desarrollo individual, adecuado posteriormente al desarrollo colectivo, en las conclusiones finales como grupo.

Vincularan los contenidos de las teorías y materiales estudiados en la experiencia en el campo.

- Optimizar la visita mediante la utilización de técnicas relativas a las visitas a sitios históricos como medios de enseñanza.

Esta gira contribuirá a la formación humanista de los jóvenes al estar en contacto directo con vestigios de nuestra historia, de nuestras raíces como pueblo que se reflejan en esta sociedad primitiva, y a la vez, desarrollara la capacidad de pensamiento, en la medida que concluyan sobre el papel e influencias jugados por los habitantes del área sobre el resto de la zona.

Un sitio con las características que presenta Barriles nos ofrece un caudal infinito de conocimientos históricos, por lo que contemplamos realizar trabajos individuales y grupales para obtener el mayor provecho del mismo. Así, vemos que la implementación de la Guía de observación, como medio fundamental para el trabajo y ulterior presentación del mismo por el alumno, constituirá el punto de apoyo de ellos y ellas en sus reflexiones. 
Otra herramienta para lograr la internalización de estos aprendizajes será el involucrar a los estudiantes en la difusión de nuestro patrimonio a través murales y exposiciones a sus compañeros, relatando sus experiencias y conclusiones sobre la importancia y relevancia del Sitio dentro de la cultura precolombina del país y dentro de nuestro patrimonio cultural como Nación.

\section{VISITAAL SITIO BARRILES}

TEMA: Sitos Arqueológicos del occidente panameño: Centro Ceremonial Barriles.

TIEMPO: Una clase (visita de campo)

OBJETIVO: Explicar la importancia del Sitio Barriles dentro del contexto histórico-social de Panamá.

Métodos: Trabajo independiente Investigación.

\section{Niveles del Conocimiento:}

Nivel Fáctico: Petroglifos

Metates

Cerámica

Estatuaria

Nivel Lógico: Centro ceremonial

Patrimonio Arqueológico

Estratificación Social

Custodios patrimoniales 
Valores a desarrollar: Laboriosidad

$$
\text { Responsabilidad }
$$

Sentido de Pertenencia

Responsabilidad ambiental.

\section{Actividades de Aprendizaje:}

1. En ruta al sitio, se le formularan algunas preguntas introductorias tales como:
* ¿ En qué sector de Chiriquí se ubica el Sitio Barriles?
* ¿Creen ustedes que el clima del área influyó en la localización del mismo?
* ¿ ¿ La ubicación de una fuente de agua benefició este asentamiento? ¿ Por qué?
* ¿ Qué restos arqueológicos creen que encontraremos en el sitio?
* ¿Qué valores de nuestro banco de valores crees que podremos identificar en la labor de los primeros pobladores del sitio y de la familia Landao?

2. Trabajarán individualmente en base a la Guía de Observación otorgada por el profesor.

3. Tomarán apuntes sobre las explicaciones de los guías del sitio y del profesor sobre las particularidades del sitio.

4. Tomarán fotografías de los lugares y objetos arqueológicos más importantes para el posterior informe.

5. Después de finalizada la visita, se le plantearán los siguientes cuestionamientos como base para su informe de campo:

- ¿ ¿ De donde proviene el nombre del sitio?

- Ubica en un mapa de Chiriquí la ubicación geográfica del sitio

- Según lo atendido en las explicaciones, ¿Por qué razones piensas que los pobladores del área inmigraron repentinamente? 
- En base a la estatuaria del sitio, ¿qué puedes concluir sobre la estratificación social? ¿ Por qué?

- ¿ Qué opinas sobre la función de custodios de este patrimonio por la familia Landao? ¿Harías tu lo mismo en su situación? ¿¿Por qué?

- ¿Qué puedes decir sobre el portentoso y cuidadoso trabajo efectuado por los pobladores de está área en la confección de los grandes metates, estatuas y demás piezas ceremoniales? ¿Qué valor de nuestro banco de datos le podemos aplicar?

- ¿QQué te parece la preparación y dedicación de esta familia no solo en los aspectos relacionados al sitio arqueológico, sino también sobre sus proyectos para el área?

- Concluye sobre la importancia del sitio Barriles en la arqueología chiricana y panameña en base a los restos históricos encontrados en el área y en la bibliografía consultiva propuesta (Panamá en el siglo XX, Adaptive Radiations in Prehistoric Panama)

IDEA RECTORA: El Centro Ceremonial Barriles es el sitio arqueológico más importante en el occidente panameño por sus evidencias que comprueban la existencia de una avanzada sociedad.

\section{ACTIVIDADES DE CIERRE.}

Para constatar la internalización del objetivo y los conocimientos adquiridos, plantearemos las siguientes interrogantes finales:

1. ¿Por qué consideras al Sitio Ceremonial Barriles como el más importante del Occidente 
panameño?

2. Concluye la importancia para la zona que tendrá el complejo turístico relacionado al Sitio y a sus áreas aledañas ¿Impactará positivamente? ¿ Por qué?

3. El papel desempeñado por la Familia Landao es digno de admirar. ¿Qué sugerencias les harías para mejorar y desarrollar al sitio y el futuro museo?

4. Actuarán como difusores de nuestro patrimonio histórico cuando, al regreso a las aulas escolares, preparen en grupos, murales informativos sobre diferentes secciones del sitio visitado, complementándolos con las respectivas explicaciones a sus compañeros.

RECURSOS: Apuntes personales de la visita al sitio Barriles

Historia de Panamá en el siglo XX. Fascículo 5

Adaptive Radiations in Prehistoric Panamá

EVALUACIÓN: Diagnóstica（preguntas previas)

Sumativa (evaluación al informe de campo)

Formativa ( papel como divulgadores del patrimonio

Histórico a través de los murales y exposi-

ciones)

\section{*El informe de la visita se entregará 9 días después de la gira*} CONCLUSIONES

A manera de Conclusión, expondremos algunas reflexiones finales sobre la importancia de las giras educativas como estrategia metodológica en la enseñanza de la Historia.

1. Mediante nuestras experiencias hemos podido constatar como las excursiones educativas 
son una excelente estrategia educativa, especialmente para los jóvenes de estos niveles (Pre media)

2. Las vivencias de los estudiantes no solo los llevan a internalizar de una manera más concreta sus conocimientos sobre las áreas visitadas, sino que a la vez, logran establecer una correlación entre los contenidos del programa con sus experiencias en el campo.

3. Las excursiones educativas son de carácter multidisciplinario, ya que además de las actividades relacionadas con el ámbito histórico, se realizan tareas y observaciones en otras materias académicas como Geografía, Ciencias Naturales, Negocios, Literatura, entre otras.

4. Debemos resaltar la importancia de la utilización de fuentes y medios en la enseñanza de la Historia, en este caso, de las fuentes primarias (museos, sitios históricos y arqueológicos, parques nacionales, etc.). Mediante actividades de este tipo, lograremos que el aprendizaje para los estudiantes sea cada vez más atractivo e interesante, a la vez que los convertimos en difusores de nuestro patrimonio histórico y cultural.

5. La evaluación que se aplica a una experiencia educativa de este tipo, es de varios tipos, a saber; Formativa, al internalizar en los estudiantes el deseo de conocer, preservar y difundir nuestro patrimonio histórico y, Sumativa, al momento de la presentación de trabajos recopilatorios de las experiencias obtenidas en los sitios visitados. 


\section{RECOMENDACIONES}

Como recomendación, en base a las experiencias obtenidas, podemos acotar lo siguiente:

Generalizar el uso, en la medida de las posibilidades, de las excursiones educativas como estrategia metodológica de aprendizaje, no solo en la enseñanza de la Historia, sino también de otras disciplinas académicas, en vista a los resultados obtenidos en las experiencias expuestas en el presente trabajo. Las excursiones también se pueden realizar en lugares cercanos a nuestros centros educativos, aprovechando la riqueza cultural de cada una de las comunidades de nuestros países. 